\title{
An Efficient Algorithm of the Unified Stochastic Particle Bhatnagar-Gross-Krook Method for the Simulation of Multi-Scale Gas Flows
}

Fei Fei ( $\nabla$ ffei@hust.edu.cn )

Huazhong University of Science and Technology

\section{Yang Ma}

Huazhong University of Science and Technology

Jie Wu

Huazhong University of Science and Technology

Jun Zhang

Beihang University

\section{Research Article}

Keywords: Multiscale flows, Stochastic particle method, Kinetic model

Posted Date: April 21st, 2021

DOI: https://doi.org/10.21203/rs.3.rs-428372/v1

License: (9) This work is licensed under a Creative Commons Attribution 4.0 International License. Read Full License

Version of Record: A version of this preprint was published at Advances in Aerodynamics on July 5th, 2021. See the published version at https://doi.org/10.1186/s42774-021-00069-8. 


\section{Abstract}

The unified stochastic particle method based on the Bhatnagar-Gross-Krook model (USP-BGK) has been proposed recently to overcome the low accuracy and efficiency of the traditional stochastic particle methods, such as the direct simulation Monte Carlo (DSMC) method, for the simulation of multi-scale gas flows. However, running with extra virtual particles and space interpolation, the previous USP-BGK method cannot be directly transplanted into the existing DSMC codes. In this work, the implementation of USPBGK is simplified using new temporal evolution and spatial reconstruction schemes. As a result, the present algorithm of the USP-BGK method is similar to the DSMC method and can be implemented efficiently based on any existing DSMC codes just by modifying the collision module.

\section{Full-text}

Due to technical limitations, full-text HTML conversion of this manuscript could not be completed. However, the manuscript can be downloaded and accessed as a PDF.

\section{Figures}

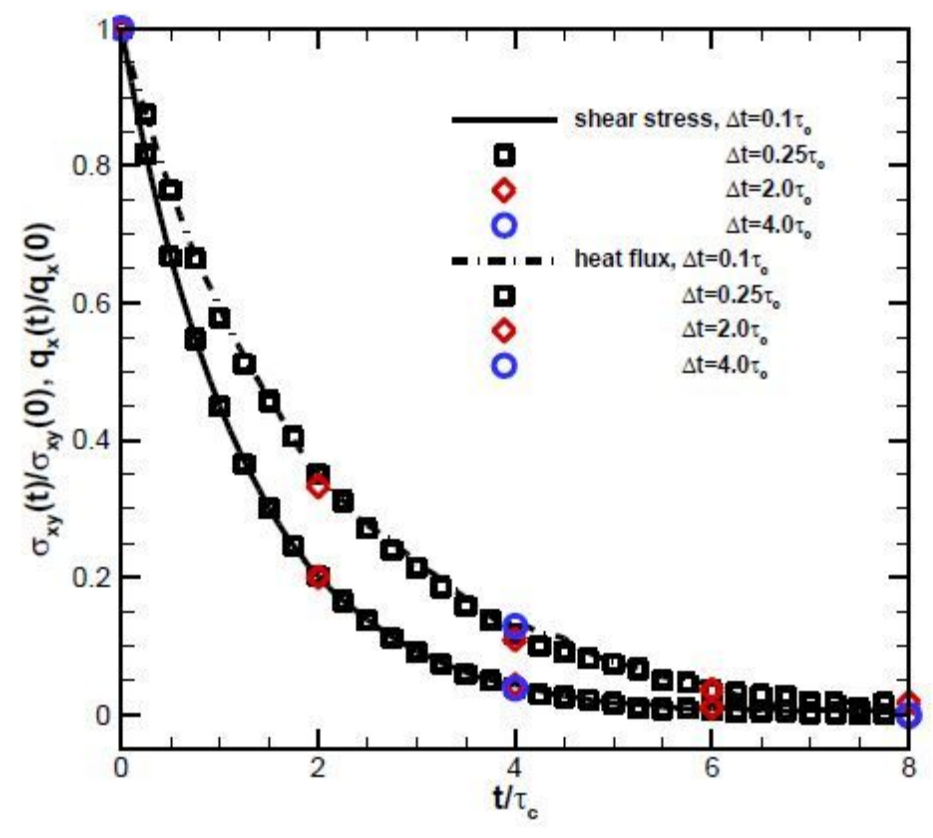

(a)

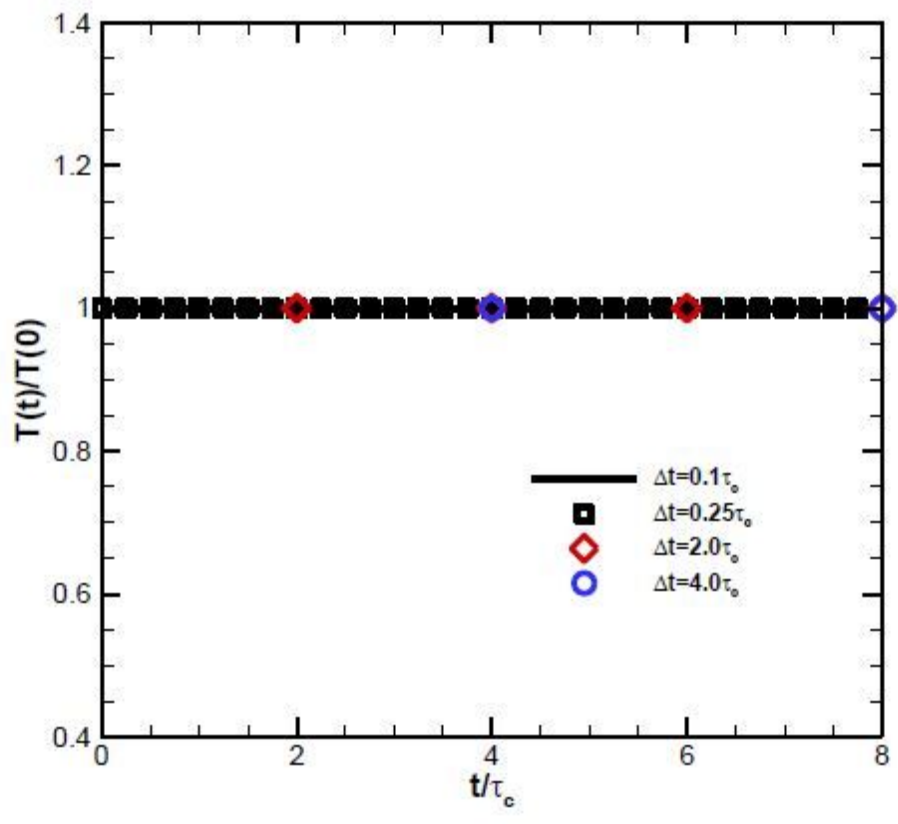

(b)

\section{Figure 1}

please see the manuscript file for the full caption 


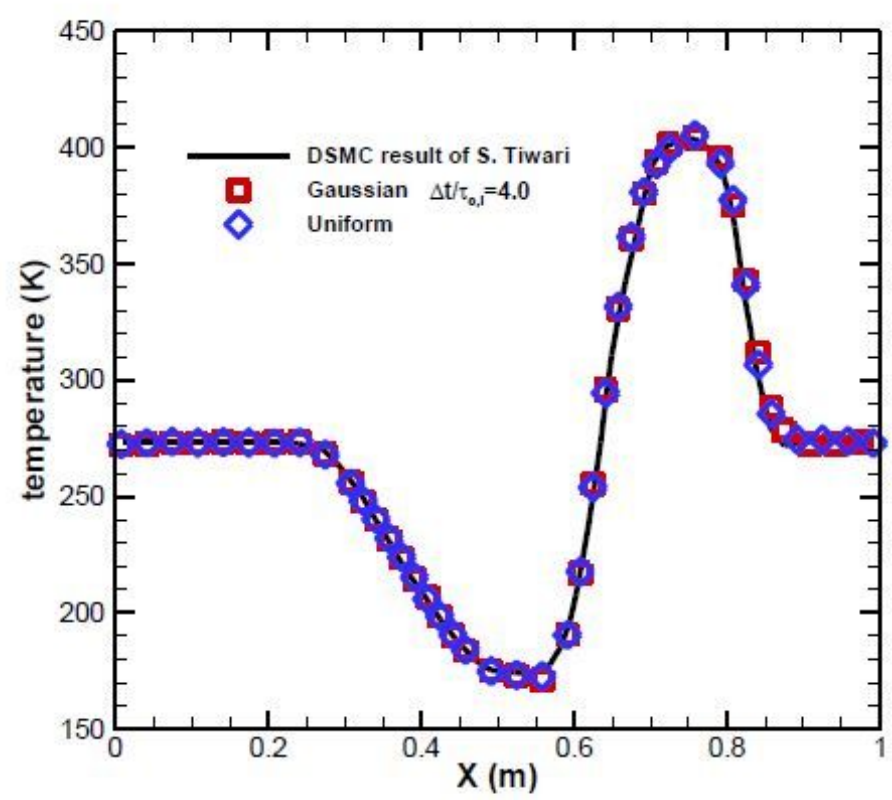

(a)

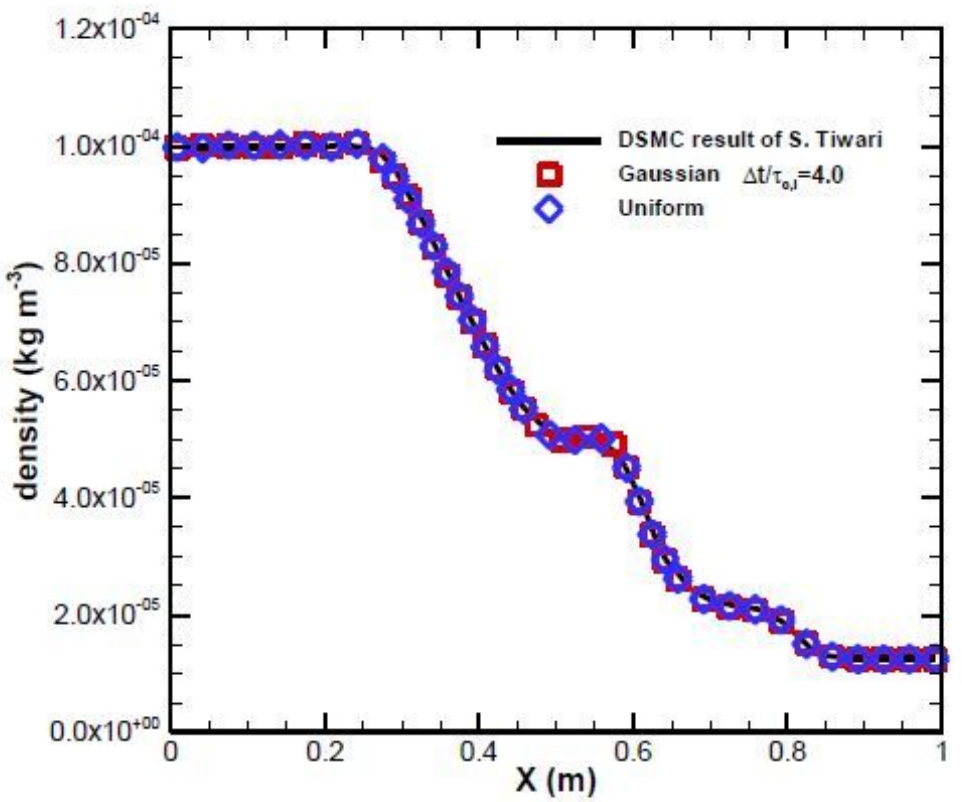

(b)

Figure 2

please see the manuscript file for the full caption 


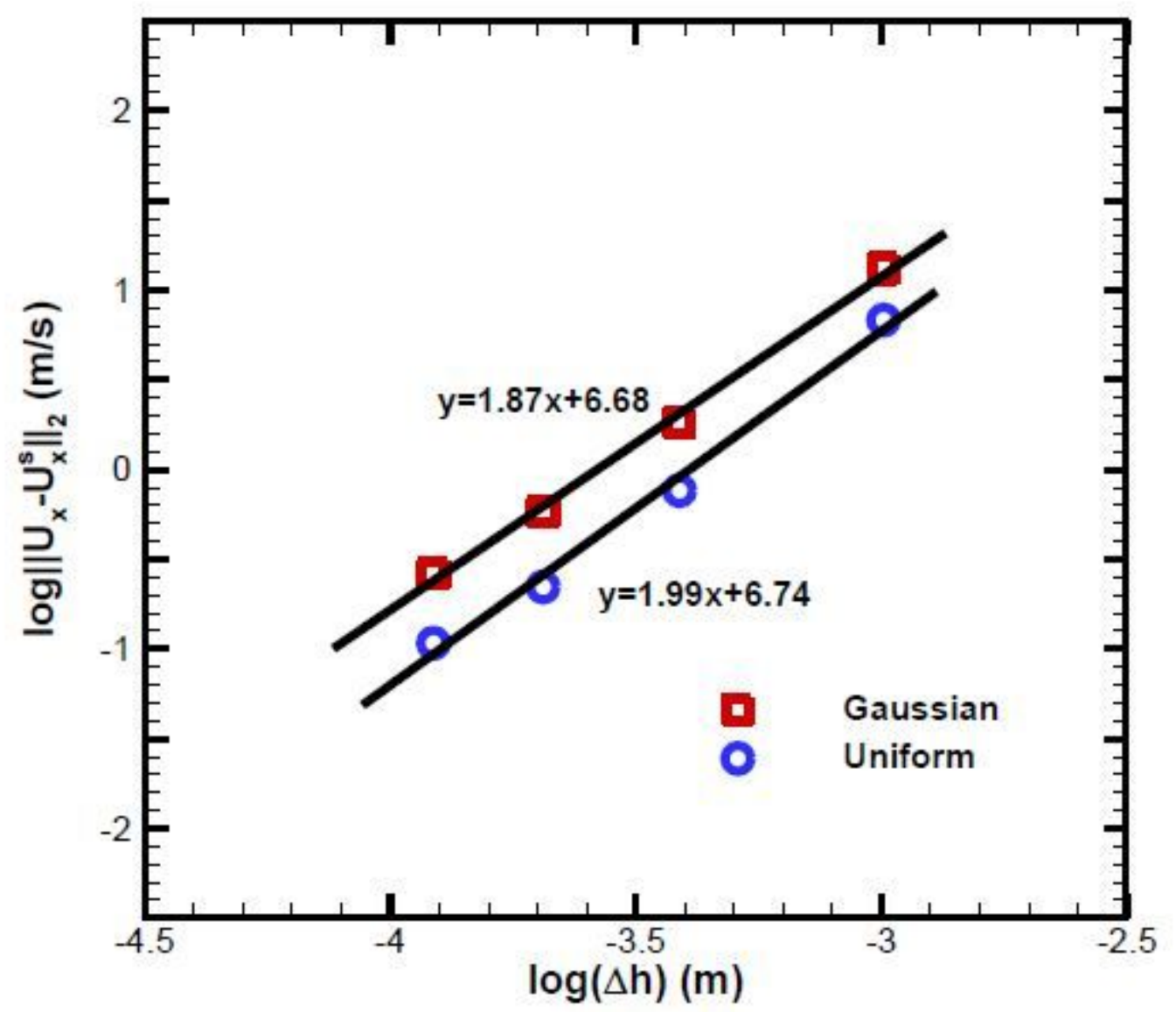

Figure 3

please see the manuscript file for the full caption 


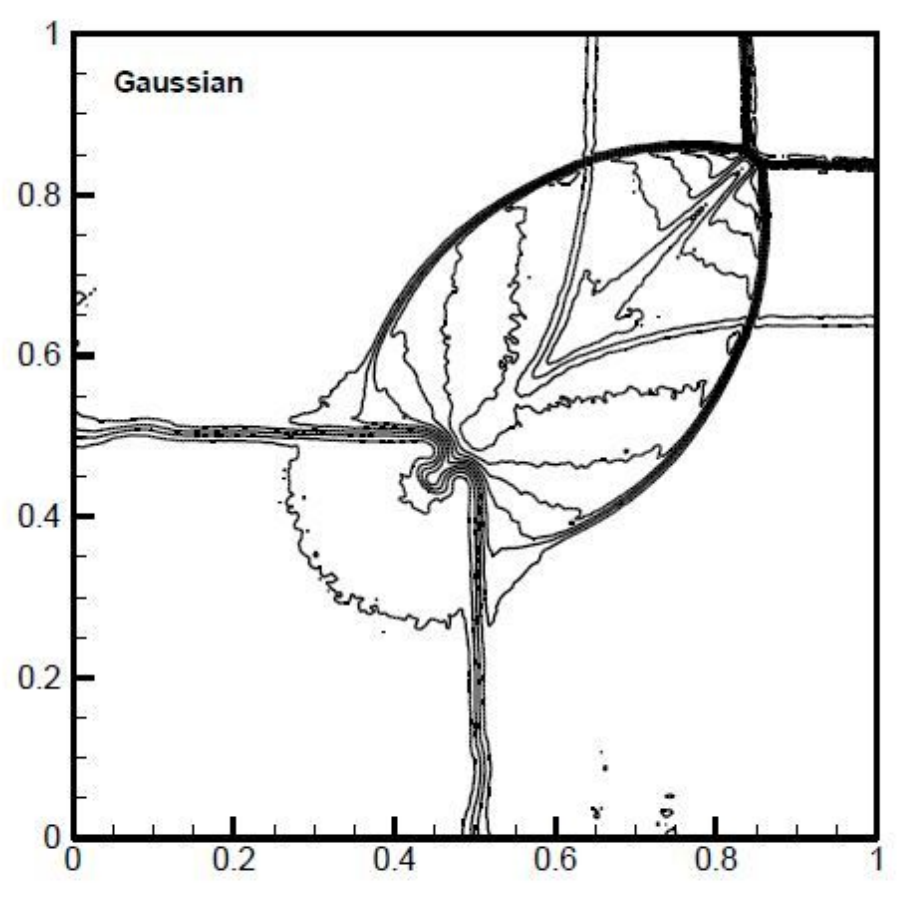

(a)

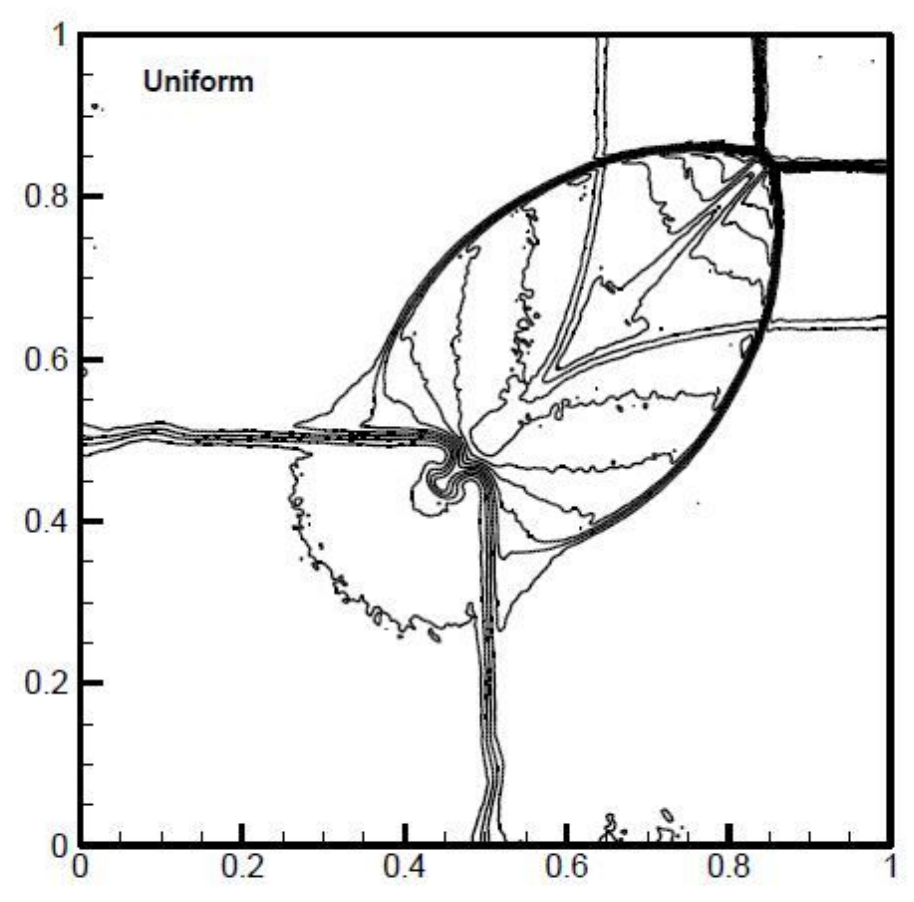

(b)

Figure 4

Density distribution of the 2D Riemann problem using the efficient USP-BGK method with (a) Gaussian and (b) uniform kernel functions. 